\title{
Las dinámicas urbanas
}

\author{
Rafael Sánchez ${ }^{1}$
}

Los centros urbanos son recipientes de poderosas dinámicas. Dichas fuerzas son ejercidas por numerosos actores que en una constante interacción, tensión y conflicto van estableciendo y modificando la morfología y estructura de los asentamientos.

En el presente número semitemático se reúnen seis artículos que dan cuenta de las consecuencias del actuar de los agentes. El primero de ellos, de Antonio Daher, acentúa la relación entre las crisis económicas y las inmobiliarias, sosteniendo que la "nueva" geografía económica no es otra que la de la securitización y las innovaciones de la ingeniería financiera que, lejos de la ubicuidad o la desterritorialización, emerge como una auténtica geografía de la financiarización. Ernesto López-Morales, aborda los intensos procesos de reestructuración urbana que ocurren en las zonas pericentrales de las ciudades chilenas, ofreciendo una lectura crítica del fenómeno de la gentrificación y evidenciando cómo las inmobiliarias realizan incrementos de renta potencial, que ocurren junto a procesos deliberados de devaluación de renta de suelo socialmente capturada, y cuya consecuencia es el desplazamiento de residentes de bajo ingreso.

Por su parte, Paola Jirón y Pablo MansiIla, analizan las barreras de accesibilidad y cómo estas se conjugan para dar cuenta de la complejidad que las personas enfrentan para acceder a las oportunidades de la ciudad, las estrategias que emplean y las diversas formas de exclusión social y urbana que a partir de ellas se desprenden. Este estudio realizado

\footnotetext{
1 Instituto de Geografía, Pontificia Universidad Católica de Chile (Chile). E-mail: rsanchez@uc.cl
}

en Santiago, permite evidenciar las múltiples barreras de accesibilidad que los viajeros encuentran diariamente en sus trayectos por la ciudad, las cuales van dando una "espesura" a la experiencia del tiempo-espacio.

En el cuarto artículo, los autores Francisca Márquez y Ricardo Truffello, indagan sobre las representaciones que subyacen en las cartografías y representaciones de un territorio conocido como La Chimba de Santiago, entre los siglos XVII y XXI. La investigación concluye que La Chimba se ha construido histórica y socialmente como un territorio de frontera, como el "otro lado" de la ciudad, como contracara de la ciudad oficial.

Siguiendo con esta perspectiva temporal, José Rosas y Elvira Pérez analizan el proceso de formación del centro histórico de Santiago de Chile, centrándose en las manzanas y edificaciones religiosas. Es posible de observar que la trama urbana, que se mantiene aparentemente constante, registra diversas modificaciones en su forma y materialidad que reflejan los cambios en la organización interna de las manzanas y sus relaciones con las calles, revelando la realidad de un orden, menos resistente al cambio de lo que en principio, se ha explicado en los textos y registrado en los documentos.

Por su parte, Jonathan Barton, Ricardo Pozo, Álvaro Román y Alejandro Salazar dan cuenta de los cambios socioespaciales que el archipiélago de Chiloé ha experimentado en las últimas décadas como consecuencia de la localización y progresiva consolidación de la industria del salmón. Concluyen que la inserción de ciudades medianas y pequeñas en los circuitos, o redes de acumulación de capital global ha generado importantes des- 
equilibrios que influyen negativamente en la posibilidad de crear procesos de desarrollo urbano más sustentables.

Los seis artículos que completan este número 56 de Revista de Geografía Norte Grande se aproximan a otras temáticas geográficas como la Educación, los desastres y la geomática. El trabajo de Andoni Arenas y Víctor Salinas, indaga sobre la Educación Geografía enfatizando que existe un giro hacia la constitución de una mirada didáctica de carácter comprensivo, basada en la renovación geográfica y educativa. En su texto, Pedro Fraile y Quim Bonastra analizan la proliferación en América Latina de las web del delito, las cuales son diferenciadas en categorías y explicando su funcionamiento e influencia espacial. Por su parte, Trinidad Larraín Donoso busca reconstruir y conocer los modos de elaboración y validación del conocimiento científico en el espacio colonial iberoamericano a través de los estudios realizados en Santiago de Chile por los científicos ilustrados José Espinosa y Tello y Felipe Bauzá en 1794. El artículo de Patricia Gutiérrez, Fernando Peña-Cortés y Marco Cisternas, demuestra que las áreas inundadas a consecuencia del tsunami de 1960 de la localidad de Corral, en el sur de Chile, fueron nuevamente repobladas y que la percepción de la población frente a este riesgo es prácticamente inexistente. María Paula Michalijos y Julio Uboldi, buscan delimitar y calcular las áreas afectadas por incendios en el Parque Provincial Ernesto Tornquist de la provincia de Buenos Aires, Argentina. Para ello proponen aplicar y comparar dos índices espectrales, uno de vegetación y otro de áreas quemadas y dos clasificaciones supervisadas. El artículo de Fermín M. Alfaro, Jaime Pizarro-Araya, Luis Letelier y Jorge Cepeda-Pizarro, documenta la composición taxonómica del orden Orthoptera para las provincias biogeográficas chilenas de Atacama y Coquimbo y establecen la distribución espacial de sus especies en relación a las formaciones vegetales para dichas áreas.

Finalmente, a los doce artículos presentados, se agregan tres reseñas de libros, y una entrevista realizada por académicos de la Facultad de Arquitectura y Urbanismo de la Universidad de Chile al destacado geógrafo Don Mitchell, quien realiza interesantes reflexiones en torno al espacio público y los movimientos sociales. 